\title{
COMPARAÇÃO DE PENETRÔMETROS NA AVALIAÇÃO DA COMPACTAÇÃO DE LATOSSOLOS
}

\author{
AMAURI N. BEUTLER ${ }^{1}$, JOSÉ F. CENTURION ${ }^{2}$, ALVARO P. SILVA ${ }^{3}$
}

\begin{abstract}
RESUMO: Diversos penetrômetros são utilizados para avaliar a resistência do solo à penetração em sistemas de uso e manejo, no entanto os valores obtidos com os mesmos divergem. O objetivo deste estudo foi comparar os resultados obtidos com três penetrômetros, em três níveis de compactação. Utilizou-se de um Latossolo Vermelho distrófico ( $\mathrm{LVd}$ ), textura média, e um Latossolo Vermelho eutroférrico (LVef), textura argilosa, cujas amostras foram coletadas na camada de 0-20 cm e compactadas em camadas, em vasos de $25 \mathrm{~cm}$ de diâmetro e $20 \mathrm{~cm}$ de altura. Determinou-se a resistência do solo à penetração com os penetrômetros de impacto, estático de anel dinamométrico e eletrônico de laboratório. Em solo compactado, o penetrômetro de impacto apresentou valores superiores de resistência à penetração, comparado aos penetrômetros de anel dinamométrico e eletrônico, porém todos foram eficientes para caracterizar a compactação. Os resultados obtidos com os penetrômetros de anel dinamométrico e eletrônico foram semelhantes.
\end{abstract}

PALAVRAS-CHAVE: resistência à penetração, atributos físicos do solo, conteúdo de água.

\section{COMPARISON OF PENETROMETERS TO EVALUATE SOIL COMPACTNESS IN OXISOLS}

\begin{abstract}
Several penetrometers have been used to evaluate soil resistance to penetration in tillage systems. However, the values obtained with them, diverge. This research was carried out with the objective of comparing results obtained with three penetrometers in three levels of compactness, using soil samples collected at 0-20 cm depth of an Oxisol (Haplustox) (LVd), medium texture, an Oxisol (Eutrustox) (LVef) and clayey texture. The soils were compacted in layers, in pots of $25 \mathrm{~cm}$ diameter and $20 \mathrm{~cm}$ height. Soil resistance to penetration with impact and and electronic dynamometrical ring penetrometers were determined. The impact penetrometer presented superior values of resistance to penetration in relation to the static and electronic dynamometrical ring penetrometers; moreover all were efficient to characterize soil compactness. The results obtained with the ring penetrometer and eletronic penetrometers were similar.
\end{abstract}

KEYWORDS: resistance to penetration, soil physical attributes, water content.

\section{INTRODUÇÃO}

A compactação do solo afeta a dinâmica da água, do ar e do calor, e pode afetar a eficiência da utilização de água, fertilizantes e herbicidas pelas plantas em função do menor desenvolvimento radicular (HAKANSSON \& VOORHEES, 1998), culminando em decréscimo de produtividade (BARBER, 1994; BEUTLER \& CENTURION, 2004; BEUTLER et al., 2006).

Para avaliar a compactação, a resistência do solo à penetração (RP) tem sido freqüentemente utilizada (FRITTON, 1990; TORMENA \& ROLOFF, 1996; CASAGRANDE, 2001; BEUTLER \& CENTURION, 2004), por ser um atributo diretamente relacionado ao crescimento das plantas (LETEY, 1985) e de fácil e rápida determinação (STOLF, 1991). Segundo BENGHOUGH \& MULLINS (1990), a RP é a melhor estimativa do impedimento mecânico do solo ao crescimento radicular. TORMENA \& ROLOFF (1996) verificaram que a RP é um indicador sensível da

\footnotetext{
${ }^{1}$ Engo ${ }^{\circ}$ Agrônomo, Pós-Doutorando, Departamento de Solos e Adubos, UNESP, Jaboticabal - SP, Fone: (0XX16) 3209.2672, amaurib@yahoo.com.br. Bolsista da FAPESP.

${ }^{2}$ Engo ${ }^{\circ}$ Agrônomo, Prof. Adjunto, Departamento de Solos e Adubos, UNESP, Jaboticabal - SP, Bolsista do CNPq.

${ }^{3}$ Eng $^{\circ}$ Agrônomo, Doutor, Departamento de Ciência do Solo, ESALQ, Piracicaba - SP, Bolsista do CNPq.

Recebido pelo Conselho Editorial em: 21-9-2004
}

Aprovado pelo Conselho Editorial em: 14-12-2006 
compactação, e TAYLOR \& GARDNER (1963) encontraram maior correlação da RP ( $\mathrm{r}=-0,96)$, comparado à densidade do solo $(\mathrm{r}=-0,59)$, com o crescimento radicular.

A RP é influenciada pela textura, conteúdo de água, densidade do solo e tipo de mineral de argila no solo (GOMES \& PEÑA, 1996). Nesse contexto, o conteúdo de água na capacidade de campo é considerado ideal para a determinação da RP, condição em que é obtida melhor correlação com a densidade do solo e o crescimento radicular (HENDERSON, 1989; ARSHAD et al., 1996), sendo a sua influência maior em solos mais argilosos (ROSOLEM et al., 1999).

Os penetrômetros rotineiramente utilizados para a avaliação da compactação são denominados em função do princípio de penetração, de estáticos, em que o conjunto é pressionado contra o solo, e a RP é registrada em um dinamômetro e, de dinâmicos, em que a haste penetra no solo em decorrência do impacto de um peso que cai em queda livre de uma altura constante (STOLF, 1991). STOLF (1991) comparou o penetrômetro de impacto com um penetrômetro estático com mola dinamométrica e verificou que, em solo arenoso, os penetrômetros apresentaram valores semelhantes, e, em solo argiloso, o penetrômetro de impacto apresentou valores superiores ao penetrômetro estático. BEUTLER et al. (2002) verificaram que a RP registrada com o penetrômetro de impacto foi superior comparado ao penetrômetro de anel dinamométrico, em maiores níveis de compactação, e a diferença aumentou no solo mais argiloso com o incremento da compactação.

Segundo HERRICK \& JONES (2002), os penetrômetros estáticos registram a RP por unidade de área, e os penetrômetros dinâmicos (penetrômetro de impacto) registram a RP por unidade de profundidade, o que não permite a comparação direta dos aparelhos. Ainda, o penetrômetro estático eletrônico determina vários valores de resistência na mesma amostra, dos quais se utiliza o valor médio de RP, e os penetrômetros de impacto e de anel dinamométrico determinam a RP máxima. Isso impossibilita a comparação direta dos penetrômetros. Entretanto, em vários trabalhos, a compactação do solo é avaliada por meio da resistência à penetração determinada com diferentes penetrômetros, e a partir dos resultados são realizadas inferências nas resistências à penetração crítica ao crescimento radicular das plantas de 2,0 MPa (TAYLOR et al., 1966).

O penetrômetro de impacto tem sido amplamente utilizado no campo para caracterizar a compactação provocada pelo uso e manejo do solo (TORMENA \& ROLOFF, 1996; CASAGRANDE, 2001), em razão do baixo custo, da não-necessidade de calibração freqüente e do fato de os resultados independerem do operador. HERRICK \& JONES (2002) verificaram que o penetrômetro de impacto é apropriado para todas as aplicações indicadas para os penetrômetros estáticos manuais e recomendado quando a constância de operação do penetrômetro estático é questionável. Porém, os autores mencionam que penetrômetros estáticos eletrônicos apresentam um método mais padronizado.

Assim, este estudo teve o objetivo de comparar valores de resistência do solo à penetração, obtidos com o penetrômetro de impacto, de anel dinamométrico e eletrônico, determinados em três níveis de compactação, em Latossolo Vermelho distrófico e Latossolo Vermelho eutroférrico.

\section{MATERIAL E MÉTODOS}

O experimento foi conduzido em Jaboticabal - SP. Utilizou-se de um Latossolo Vermelho distrófico, típico, textura média, A moderado, caulinítico hipoférrico (LVd) e um Latossolo Vermelho eutroférrico, típico, textura argilosa, A moderado, caulinítico-oxídico (LVef), cujas amostras foram coletadas na camada de $0-20 \mathrm{~cm}$ e passadas em peneira de 4,0 $\mathrm{mm}$. O LVd e o LVef apresentaram, respectivamente, 14 e $37 \mathrm{~g} \mathrm{~kg}^{-1}$ de matéria orgânica, 271 e $517 \mathrm{~g} \mathrm{~kg}^{-1}$ de argila, 42 e $256 \mathrm{~g} \mathrm{~kg}^{-1}$ de silte, 687 e $227 \mathrm{~g} \mathrm{~kg}^{-1}$ de areia.

$\mathrm{O}$ delineamento experimental foi inteiramente casualizado, em esquema fatorial $3 \times 3$ (três penetrômetros e três níveis de compactação), nos dois solos, com três repetições. 
O solo foi colocado em vasos cilíndricos de PVC, com capacidade de $0,0098 \mathrm{~m}^{3}(20 \mathrm{~cm}$ de altura e $25 \mathrm{~cm}$ de diâmetro), em camadas de $3 \mathrm{~cm}$. Cada camada foi compactada através da queda livre de um êmbolo de $7 \mathrm{~kg}$, da altura de $60 \mathrm{~cm}$, no centro geométrico de uma superfície de madeira com diâmetro ligeiramente inferior ao do vaso, sendo a compactação aumentada com o número de impactos por camada. Dessa forma, foram estabelecidos três níveis de compactação caracterizados pela densidade do solo de 1,$17 ; 1,41 \mathrm{e} 1,58 \mathrm{Mg} \mathrm{m}^{-3}$ e 0,$93 ; 1,15$ e 1,27 $\mathrm{Mg} \mathrm{m}^{-3}$, no LVd e no LVef, respectivamente. Os conteúdos de água após a compactação foram de 0,12 e $0,27 \mathrm{~kg} \mathrm{~kg}^{-1}$, para o LVd e LVef, respectivamente. A densidade do solo foi determinada com auxílio de anéis volumétricos com $4,8 \mathrm{~cm}$ de diâmetro e $3,0 \mathrm{~cm}$ de altura.

A RP foi determinada com o penetrômetro de impacto (modelo IAA/ Planalsucar-Stolf), com o penetrômetro de anel dinamométrico, ambos com ângulo de cone de $30^{\circ}$, conforme recomendado pela ASAE (1976), e o penetrômetro estático eletrônico com ângulo de cone de $60^{\circ}$. Com o penetrômetro de anel dinamométrico e com o penetrômetro eletrônico, os valores de resistência à penetração foram determinados na profundidade de $3-6 \mathrm{~cm}$, sendo que, para o penetrômetro de anel dinamométrico, o valor de RP máximo foi obtido da média de cinco subdeterminações.

A determinação da resistência à penetração, com o penetrômetro de impacto, foi realizada com êmbolo de $1 \mathrm{~kg}$, ao invés de $4 \mathrm{~kg}$ (padrão), apenas no menor nível de compactação, em função do peso excessivo do aparelho que não permitiu a avaliação nessa condição. A transformação da penetração da haste do aparelho no solo (cm/impacto), em resistência à penetração, foi obtida pela expressão dos "holandeses" simplificada por STOLF (1991), a seguir:

$$
\mathrm{RP}=\frac{\mathrm{Mg}+\mathrm{mg}+\left(\frac{\mathrm{M}}{\mathrm{M}+\mathrm{m}} \frac{\mathrm{Mgh}}{\mathrm{x}}\right)}{\mathrm{A}}
$$

em que,

$\mathrm{RP}$ - resistência à penetração, $\mathrm{kgf} \mathrm{cm}^{-2}$;

M - massa do êmbolo (4 kg ) ( $\mathrm{Mg}=4 \mathrm{kgf}) ;(1 \mathrm{~kg}$ no menor nível de compactação);

$\mathrm{m}$ - massa do aparelho sem êmbolo $(3,2 \mathrm{~kg})(\mathrm{mg}=3,2 \mathrm{kgf})$;

$\mathrm{h}$ - altura de queda do êmbolo $(40 \mathrm{~cm})$;

$\mathrm{x}$ - penetração da haste do aparelho, $\mathrm{cm}_{\text {impacto }}{ }^{-1}$, e

A - área do cone, $1,29 \mathrm{~cm}^{2}$.

A resistência à penetração com o penetrômetro de anel dinamométrico foi determinada utilizando cone com diâmetro da base de 2,84;2,20 e $1,20 \mathrm{~cm}$, diminuindo a área do cone com o incremento da compactação do solo. O valor obtido no relógio de leitura foi transformado em kgf cm$~^{-2}$ pela equação linear de calibração a seguir:

$$
\mathrm{RP}=(1,0444+0,2998 \mathrm{y}) / \mathrm{a}
$$

em que,

$$
\begin{aligned}
& \mathrm{RP} \text { - resistência à penetração, } \mathrm{kgf} \mathrm{cm}^{-2} \text {; } \\
& \mathrm{y} \text { - leitura no relógio, e } \\
& \mathrm{a} \text { - área do cone, } \mathrm{cm}^{2} .
\end{aligned}
$$

Os valores de RP $\left(\mathrm{kgf} \mathrm{cm}^{-2}\right)$ foram multiplicados pelo fator 0,098 para obtenção da RP em MPa.

Para a determinação da resistência à penetração com o penetrômetro eletrônico, as amostras indeformadas foram coletadas, em cada nível de compactação, em cilindros de $4,8 \mathrm{~cm}$ de diâmetro e 3,0 cm de altura, saturadas e submetidas às tensões de 0,$006 ; 0,01 ; 0,033 ; 0,06$ e 0,3 MPa. Após as amostras atingirem o equilíbrio, foi determinada a resistência do solo à penetração, utilizando penetrômetro estático eletrônico de laboratório, com velocidade constante de penetração de $1 \mathrm{~cm} \mathrm{~min}^{-1}$ e cone com área da base de $0,037 \mathrm{~cm}^{2}$. O penetrômetro é equipado com atuador linear e 
célula de carga de $20 \mathrm{~kg}$ acoplada a um microcomputador para a aquisição dos dados. A resistência à penetração foi determinada no centro geométrico de cada amostra, na profundidade de $1 \mathrm{a} 2 \mathrm{~cm}$, obtendo-se uma leitura por $0,01 \mathrm{~cm}$, as quais foram utilizadas para a obtenção da resistência média à penetração em cada amostra. A partir dos valores obtidos com o penetrômetro eletrônico, ajustouse uma equação de regressão entre a RP e o conteúdo de água, nas diferentes tensões, em cada nível de compactação. Essa equação permitiu obter a resistência à penetração no conteúdo de água de $0,12 \mathrm{~kg} \mathrm{~kg}^{-1}$ para o LVd e $0,27 \mathrm{~kg} \mathrm{~kg}^{-1}$ para o LVef.

Foi utilizado o teste de Tukey, a 5\% de probabilidade, para a comparação das médias, e foram realizadas correlações de Pearson entre os valores de RP obtidos pelos diferentes penetrômetros.

\section{RESULTADOS E DISCUSSÃO}

Na Tabela 1, são apresentados os valores de resistência do solo à penetração obtidos com os penetrômetros. Os três penetrômetros foram eficientes na diferenciação dos três níveis de compactação, nos dois solos. Entretanto, os valores determinados divergiram nos maiores níveis de compactação e, no menor nível de compactação, os penetrômetros determinaram valores semelhantes, confirmando os resultados obtidos por STOLF (1991) e BEUTLER et al. (2002).

TABELA 1. Resistência do solo à penetração, determinada com os penetrômetros de impacto, de anel dinamométrico e eletrônico, no Latossolo Vermelho distrófico, textura média (LVd) e do Latossolo Vermelho eutroférrico, textura argilosa (LVef), nos níveis de compactação.

\begin{tabular}{|c|c|c|c|c|c|c|c|}
\hline \multirow{2}{*}{\multicolumn{2}{|c|}{$\begin{array}{l}\mathrm{L} \\
\text { Densidade Penetrômetro }\end{array}$}} & \multicolumn{2}{|l|}{$\mathrm{Vd}$} & \multicolumn{4}{|c|}{ LVef } \\
\hline & & Penetrômetr & Penetrômetro & Densidade & Penetrômetr & o Penetrômetro & Penetrômetro \\
\hline do Solo & Impacto & Anel & Eletrônico & do Solo & Impacto & Anel & Eletrônico \\
\hline 1,17 & $0,60 \mathrm{Ca}$ & $0,47 \mathrm{Ca}$ & $0,54 \mathrm{Ca}$ & 0,93 & $0,54 \mathrm{Ca}$ & $0,39 \mathrm{Ca}$ & $0,40 \mathrm{Ca}$ \\
\hline 1,41 & 2,97 Ba & 2,83 Ba & 2,73 Ba & 1,15 & $3,00 \mathrm{Ba}$ & $2,25 \mathrm{Bb}$ & $1,91 \mathrm{Bb}$ \\
\hline 1,58 & 4,40 Aa & $3,93 \mathrm{Ab}$ & $3,61 \mathrm{Ab}$ & 1,27 & 4,96 Aa & $3,95 \mathrm{Ab}$ & $3,40 \mathrm{Ab}$ \\
\hline C.V. $(\%)$ & & 6,9 & & & & 12,1 & \\
\hline
\end{tabular}

Médias seguidas pela mesma letra maiúscula na coluna e minúscula na linha não diferem entre si $(\mathrm{P} \leq 0,05)$.

O penetrômetro de impacto registrou maiores valores de RP no LVd, $(4,40 \mathrm{MPa})$ no maior nível de compactação, e no LVef, a partir do segundo nível de RP (3,00 MPa), comparado aos penetrômetros estáticos de anel dinamométrico e eletrônico, corroborando BEUTLER et al. (2002) e STOLF (1991). Segundo STOLF (1991), nos meios sujeitos a compressões elásticas (solos argilosos), a resistência dinâmica apresenta-se maior que a estática, e a diferença percentual aumenta com a resistência do meio. Verificou-se que, no LVef, essa diferença ocorreu a partir do segundo nível de compactação, atribuído ao maior conteúdo de argila do LVef que confere maior coesão entre as partículas e maior resistência à penetração.

Essas diferenças entre penetrômetros estão associadas ao princípio de funcionamento dos aparelhos, em que o penetrômetro de impacto apresenta princípio diferenciado comparado aos penetrômetros estáticos de anel dinamométrico e eletrônico, nos quais é exercida uma pressão contra o solo e determina-se a RP. Já no penetrômetro de impacto, é realizada uma série de cálculos, explicitados em STOLF (1991). Ainda, o penetrômetro de impacto registra a RP máxima por unidade de profundidade comparado aos penetrômetros estáticos que determinam a RP por unidade de área (HERRICK \& JONES, 2002), e o penetrômetro eletrônico, com velocidade de penetração de $1 \mathrm{~cm} \mathrm{~min}^{-1}$, determina o valor médio de RP. Nesse aspecto, verificou-se que os valores obtidos com o penetrômetro eletrônico e com o penetrômetro de anel dinamométrico foram semelhantes, mesmo com o penetrômetro eletrônico utilizando a RP média e o penetrômetro de anel dinamométrico a RP máxima, possivelmente relacionado à homogeneidade da compactação do solo realizada no vaso. 
No valor considerado limitante ao crescimento radicular das plantas, 2,0 MPa (TAYLOR et al. (1966) ou de 2,0 a 3,0 limitante à produtividade de soja (BARBER, 1994; BEUTLER \& CENTURION, 2004; BEUTLER et al., 2006), os resultados obtidos com os penetrômetros divergiram apenas no solo argiloso (LVef), com valores superiores determinados pelo penetrômetro de impacto, comparado aos penetrômetros estáticos, corroborando STOLF (1991) e BEUTLER et al. (2002), que obtiveram valores superiores para o penetrômetro de impacto comparado ao penetrômetro de anel dinamométrico. Por sua vez, no terceiro nível de compactação, o penetrômetro de impacto apresentou valores absolutos superior aos penetrômetros estáticos de anel dinamométrico e eletrônico, nos dois solos. Isso permite inferir que, em solos compactados, o penetrômetro de impacto determina valores superiores de RP, não permitindo sua comparação direta com valores críticos, às plantas, de RP obtidos com penetrômetros estáticos eletrônicos. Porém, o penetrômetro de impacto tem sido muito utilizado na identificação da compactação do solo e de camadas compactadas em sistemas de uso e manejo de culturas anuais e em cana-deaçúcar (TORMENA \& ROLOFF, 1996; CASAGRANDE, 2001).

Os penetrômetros apresentaram altas correlações entre si $(r>0,96)$ (Tabela 2), indicando que, com o aumento da compactação do solo, esses determinam maiores valores, porém de magnitudes diferenciadas. Ainda, os penetrômetros apresentaram altas correlações com a densidade e a porosidade do solo, sendo correlação positiva com a densidade do solo e negativa com o volume total de poros, concordando com os estudos de ROSOLEM et al. (1999) e BEUTLER et al. (2002), que encontraram altas correlações entre a resistência à penetração e a densidade do solo.

TABELA 2. Correlações de Pearson entre os valores de resistência à penetração determinados com os penetrômetros e desses com atributos físicos do Latossolo Vermelho distrófico, textura média (LVd) e do Latossolo Vermelho eutroférrico, textura argilosa (LVef).

\begin{tabular}{|c|c|c|c|c|c|c|c|c|}
\hline \multirow[b]{2}{*}{ Penetrômetro } & \multicolumn{4}{|c|}{$\mathrm{LVd}$} & \multicolumn{4}{|c|}{ LVef } \\
\hline & $\begin{array}{c}\text { Penetrômetro } \\
\text { Anel }\end{array}$ & $\begin{array}{c}\text { Penetrômetro } \\
\text { Eletrônico }\end{array}$ & $\begin{array}{c}\text { Densidade } \\
\text { do Solo }\end{array}$ & $\begin{array}{c}\text { Volume Total } \\
\text { de Poros }\end{array}$ & $\begin{array}{c}\text { Penetrômetro } \\
\text { Anel }\end{array}$ & $\begin{array}{c}\text { Penetrômetro } \\
\text { Eletrônico }\end{array}$ & $\begin{array}{c}\text { Densidade } \\
\text { do Solo }\end{array}$ & $\begin{array}{c}\text { Volume Total } \\
\text { de Poros }\end{array}$ \\
\hline Impacto & $0,99^{1}$ & 0,98 & 0,90 & $-0,95$ & 0,98 & 0,96 & 0,94 & $-0,81$ \\
\hline Anel & -- & 0,99 & 0,88 & $-0,98$ & -- & 0,99 & 0,96 & $-0,82$ \\
\hline Eletrônico & -- & -- & 0,86 & $-0,99$ & -- & -- & 0,97 & $-0,86$ \\
\hline
\end{tabular}

${ }^{1}$ As correlações foram significativas a $1 \%$ de probabilidade.

\section{CONCLUSÕES}

O penetrômetro de impacto determinou valores superiores de RP em solos compactados, porém os penetrômetros de anel dinamométrico e eletrônico também foram eficientes na caracterização da compactação.

Os resultados obtidos com o penetrômetro estático de anel dinamométrico e com o eletrônico foram semelhantes.

\section{REFERÊNCIAS}

ASAE. AMERICAN SOCIETY OF AGRICULTURAL ENGINEERS. Soil cone penetrometer. In: ASAE. Agricultural Engineers Yearbook. St. Joseph, 1976. p.368-369 (ASAE Report, 313.1).

ARSHAD, M.A.; LOWERY, B.; GROSSMAN, B. Physical tests for monitoring soil quality. In: DORAN, J.W.; JONES, A.J. Methods for assessing soil quality. Madison: Soil Science Society of America, 1996. p.123-41 (SSSA Special publication 49).

BARBER, R.G. Persistence of loosened horizons and soybean yield increases in Bolivia. Soil Science Society of America Journal, Madison, v.58, n.3, p.943-50, 1994.

BENGHOUGH, A.G.; MULLINS, C.E. Mechanical impedance to root growth: a review of experimental techniques and root growth responses. Journal of Soil Science, Oxford, v.41, n.3, p.341-58, 1990. 
BEUTLER, A.N.; CENTURION, J.F. Compactação do solo no desenvolvimento radicular e na produtividade de soja. Pesquisa Agropecuária Brasileira, Brasília, v.39, n.6, p.581-8, 2004.

BEUTLER, A.N.; CENTURION, J.F.; SILVA, A.P.; BARBOSA, J.C. Intervalo hídrico ótimo e produtividade de cultivares de soja. Revista Brasileira de Engenharia Agrícola e Ambiental, Campina Grande, v.10, n.3, p.639-45, 2006.

BEUTLER, A.N.; CENTURION, J.F.; SOUZA, Z.M.; SILVA, L.M. Utilização dos penetrômetros de impacto e de anel dinamométrico em Latossolos. Engenharia Agrícola, Jaboticabal, v.22, n.2, p.191-9, 2002.

CASAGRANDE, A.A. Compactação e manejo do solo na cultura da cana-de-açúcar. In: MORAES, M.H.; MÜLLER, M.M.L.; FOLONI, J.S.S. (Ed.). Qualidade física do solo: métodos de estudo - sistemas de preparo e manejo do solo. Jaboticabal: FUNEP, 2001. p.150-97.

FRITTON, D.D. A standard for interpreting soil penetrometer measurements. Soil Science, Baltimore, v.150, n.2, p.542-51, 1990.

GOMES, A. da S.; PEÑA, Y.A. Caracterização da compactação através do uso do penetrômetro. Lavoura Arrozeira, Porto Alegre, v.49, n.426, p.18-20, 1996.

HAKANSSON, I.; VOORHEES, W.B. Soil compaction. In: LAL, R.; BLUM, W.H.; VALENTINE, C.; STEWARD, B.A. (Ed.). Methods for assessment of soil degradation: advances in soil science. Boca Raton: CRS Press, 1998. p.167-79.

HENDERSON, C.W.L. Using a penetrometer to predict the effects of soil compaction on the growth an yield of wheat on uniform, sandy soils. Australian Journal of Agricultural Research, Melbourne, v.40, n.3, p.497-508, 1989.

HERRICK, J.E.; JONES, T.L. A dynamic cone penetrometer for measuring soil penetration resistance. Soil Science Society of America Journal, Madison, v.66, n.4, p.1320-4, 2002.

LETEY, J. Relationship between soil physical properties and crop production. Advances in Soil Science, New York, v.1, n.1, p.277-94, 1985.

ROSOLEM, C.A.; FERNANDEZ, E.M.; ANDREOTTI, M.; CRUSCIOL, C.A.C. Crescimento radicular de plântulas de milho afetado pela resistência do solo à penetração. Pesquisa Agropecuária Brasileira, Brasília, v.34, n.5, p.821-8, 1999.

STOLF, R. Teoria e teste experimental de fórmulas de transformação dos dados de penetrômetro de impacto em resistência do solo. Revista Brasileira de Ciência do Solo, Campinas, v.15, n.2, p.229-35, 1991.

TAYLOR, H.; GARDNER, H. Penetration of cotton seedling taproots as influenced by bulk density, moisture content, and strength of soil. Soil Science, Baltimore, v.96, n.3, p.153-6, 1963.

TAYLOR, H.M.; ROBERSON, G.M.; PARKER Jr., J.J. Soil strength-root penetration relations to medium to coarse-textured soil materials. Soil Science, Baltimore, v.102, n.1, p.18-22, 1966.

TORMENA, C.A.; ROLOFF, G. Dinâmica da resistência à penetração de um solo sob plantio direto. Revista Brasileira de Ciência do Solo, Campinas, v.20, n.2, p.333-39, 1996. 